\title{
Technological approach to development of adaptive e-learning system
}

\author{
Victoria Shershneva ${ }^{1}$, Yulia Vainshtein ${ }^{1, *}$, Tatiana Kochetkova $^{1}$, Roman Esin $^{1}$ \\ ${ }^{1}$ Siberian Federal University, Kirenskogo st., 26, Krasnoyarsk, 660074, Russia
}

\begin{abstract}
Adaptation of learning process for students with regard to their individual characteristics has currently become topical. The article proposes a technological approach to development of adaptive e-learning system, principles of its elaboration and description its structure and components. The scientific novelty of the study consists in structuring the educational content as a hierarchy of terms, original methods and algorithms of adapting learning material, and the learning outcomes assessment model which provides for the assessment of the level of subject competence development. The structure of the system which includes the educational content model, the user model, the adaptation model, and the learning outcomes assessment model is presented in the article. The proposed approach to development the educational content model is based on the integration and development of the methods of logical-andgnoseological concept analysis with graph theory methods. The adaptive elearning course of a mathematical discipline is developed and implemented into educational process. System of web-based teaching includes a set of organizational and pedagogical conditions contributing for student to acquire knowledge and experience, to develop the skills which result in developing competence required for his or her professional activities. Materials of this study are of interest for both teachers who develop electronic educational courses and managers of educational institutions interested in implementing such courses into educational process
\end{abstract}

\section{Introduction}

Nowadays global educational system is greatly influenced by rapid advancement of information and communication technology. Traditional educational technologies are being replaced by e-learning. Thus, Russian Federation Government Programme titled "Advancement of Education" points out the necessity of implementing of modern digital educational environment as a priority project, including the sphere of higher education [1]. Active use of e-learning courses in teaching modern "digital generation" living in the world of electronic culture is an integral part of education which concerns all university disciplines including mathematical ones [2].

Basing on the definition of the "electronic learning resource" stated in the Russian Federation National Standard [3], we understand the adaptive e-learning course of a

\footnotetext{
* Corresponding author: YWeinstein@sfu-kras.ru
} 
discipline as a learning resource presented in electronic digital form which includes a structure and a content area and provides for the possibility of adaptation depending on student individual characteristics.

The development of e-learning in educational institutions moves towards creating elearning courses based on learning management systems, which provide ample opportunities for both teachers and students [4].

The review [5] identifies five main technologies used in adaptive educational systems: adaptive presentation, adaptive navigation support, curriculum sequencing, intelligent analysis of student's solutions, and interactive problem solving support.

Over the past few years the leading Russian universities have been working upon the projects on development and implementation of electronic learning resources, including adaptive ones, into educational process [6-9]. However, there is no coherent concept of web-based teaching at the moment. Consequently, the creation of the adaptive system of web-based teaching as well as principles of its development has become topical.

The purpose of this article is to create technological approach to development of adaptive e-learning system of web-based teaching, to describe its structure and components as well as the principles of its development.

\section{Materials and Methods}

As a pedagogical basis for creating the adaptive system of web-based teaching we use the poliparadigmal approach which is defined as an open and consistent cluster of approaches to teaching, the integrated use of which has synergistic effect [10-11].

We also follow the didactic principles of modern higher education. In particular, the system of web-based teaching includes a set of organizational and pedagogical conditions contributing for student to acquire knowledge and experience, to develop the skills which result in developing competence required for his or her professional activities [2, 12]. When designing educational content, the strategy of microlearning is used, which consists in structuring the whole course material in small chunks [13-15].

We use modern approaches and methods of teaching mathematics in the creation of the adaptive e-learning course of a mathematical discipline in the frame of the proposed adaptive system [16-18].

\section{Results of the Study}

We propose the concept of adaptive web-based teaching relying on the following principles:

- personalisation of the learning process, which allows students to build an individual educational trajectory and to create a personal space of educational materials;

- variability - educational content has various forms of presentation;

- education periodicity - automatic return to the studied topic content represented in a different form;

- filling gaps in knowledge and skills gained earlier;

- motivational and intellectual involvement of students into the learning process;

- aiming at the achievement of learning outcomes;

- integrity - formation of cohesive comprehension of a discipline by students;

- relevance - educational content should be relevant for students and correlate with the context of their future professional activities; 
- the teacher's role is redesigned from a knowledge broadcaster to the organiser and the coordinator of the learning process who provides advice for students.

These principles are implemented in the creation of the adaptive system of web-based teaching which consists of the educational content model, the user model, the adaptation model, and the assessment model for assessing learning outcomes (Figure 1).

When building the educational content model, we use the approach based on the integration of the methods of Voishvillo's logical-and-gnoseological concept analysis with graph theory methods. The use of the hierarchy of concepts allows visualising the logical structure of the educational content, determining the sequence of studying the material, and exercising control over the results of course mastering. The subject area is formalised as a complex system of fundamental, basic, key, and specific concepts.

The concept tree is used as the basis for identifying the smallest chunks of theoretical material which we call terms. A term implies a sequence of semantic facts and procedural rules which have logical completeness [19]. Each term constitutes a fragment of the concept tree.

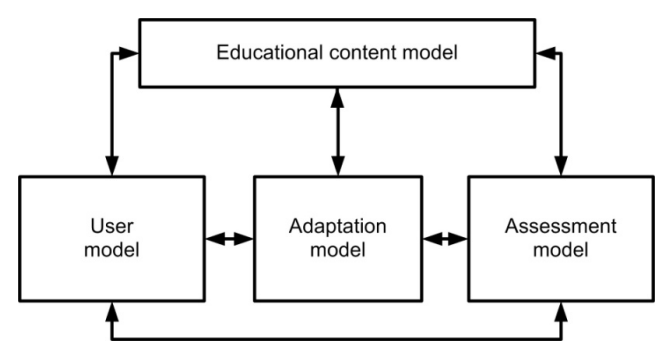

Fig. 1. Structural scheme of the adaptive system of web-based teaching

Using the strategy of microlearning we define the following criteria to include concepts into terms:

- volume limitation - each term contains no more than five concepts of the tree; in case the concept has large volume, it can be allocated to a specific term;

- completeness - when developing the term, we follow the principle of uniting small structural units into large ones, that is, the term is formed of the concept and the smaller concepts associated with it;

- testability - the level of knowledge and comprehension of all the concepts within the term can be tested.

The terms are studied sequentially: from the fundamental concepts to the basic ones and then from the key concepts to the specific ones. It allows correlating the concepts of the term with their place in the overall subject area of the discipline and contributes to the formation of its cohesive comprehension. To sum up, the educational content is structured as a sequence of terms studied in a certain order covering the whole course material (Figure 2).

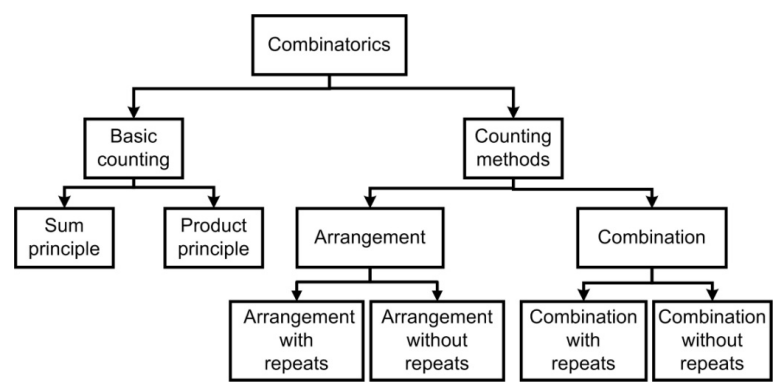

Fig. 2. Fragment of the concept tree for Discreet Mathematics discipline 
The user model of the adaptive system of web-based teaching contains information about students which is necessary to adapt the educational content to their individual characteristics and to control learning process in e-learning environment. The adaptation model of the system of web-based teaching includes an automated navigation system and the adaptation of educational content accounting for the individual characteristics of the student. To adapt the educational content, each term is provided in three different versions, which differ in the level of detail and the form of presenting: text, graphics, tables, audio and video materials, and interactive resources. Navigation on educational content is carried out on the basis of the achieved level of learning material [20].

The assessment model of the adaptive system is intended to determine the level of subject competence development of the student by assessing all its components: knowledge component of the competence, skill component of the competence, motivational component of the subject competence and reflective component (Figure 3).

Fig. 3. Subject competence structure

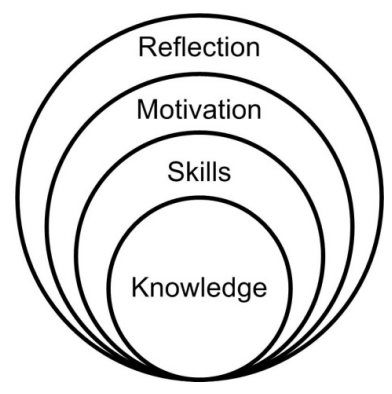

The following testing and assessing materials were developed:

- a placement test to assess prior knowledge and determine the students individual characteristics and their level of readiness to study the discipline;

- tests on terms to assess the level of knowledge and comprehension of the current material;

- tasks for independent practice with answer keys;

- tests-simulators;

- progress tests for each module of the discipline;

- applied and professionally oriented problems to determine student readiness to use the acquired knowledge and skills in the future profession;

- a final test.

The process of learning outcomes assessment is automated and it starts with evaluation of the assimilation of the therm material (knowledge component of the competence). The process is fulfilled by performing tests on terms. The ability to operate with concepts (skill component of the competence) is checked with the help of the progress tests for each module of the discipline. The level of skill development is confirmed with tests-simulators performed during the limited period of time. Applied and professionally oriented problems are used to assess the motivational component of the subject competence. The solution of such problems allows determining if the student is ready to use the acquired knowledge and skills in the future profession. To assess the reflective component two attempts are provided in all tests on terms. After taking the test for the first time the student receives an immediate response on his or her solution. If there are any mistakes, the student can think them over and has the opportunity to have the second attempt after studying the material presented in a different version. 
After assessing all the components, we can make the conclusion concerning the level of subject competence development of the student being taught in the e-learning environment. To sum up, the developed adaptive system consisting of the educational content model, the user model, the adaptation model and the assessment model, all interrelated to each other, allows implementing the adaptive web-based teaching and assessing the level of subject competence development of students [21].

\section{Conclusions}

In this article a unique structure of the adaptive system of web-based teaching is described. The scientific novelty of the study consists in structuring the educational content as a hierarchy of terms, original methods and algorithms of adapting learning material, and the learning outcomes assessment model which provides for the assessment of the level of subject competence development.

The adaptive e-learning course running on Moodle LMS was developed basing on the adaptive system proposed for Discrete Mathematics discipline. It was successfully implemented into the educational process of first year engineering students majoring in Information Technology at Siberian Federal University.

The use of the AELC enables the student to build an individual educational trajectory, to form a personal space of educational materials which correspond to his or her individual characteristics, to organise a flexible learning schedule with constant self-monitoring of learning results, and to improve the quality of the acquired knowledge and skills. A questionnaire among students showed that use of the AELC contributed to the formation of cohesive comprehension of the discipline, increased motivation for study the course and minimised psycho-emotional stress.

Basing on the studying experience with the AELC the students mentioned the following positive factors: an opportunity of studying the material delivered in a user-friendly form; boosting the efficiency of classroom work caused by the fact that students attend classes being familiar with the theoretical material; an opportunity to practise at any convenient time and at the individual pace.

The reported study was funded by RFBR according to the research project №18-013-00654

\section{References}

1. State Programme of the Russian Federation "Advancement of Education", Approved by the resolution of the Russian Federation government on 26.10.2017, no. 1642.

2. V.A. Shershneva, L.V. Shkerina, V.N. Sidorov, T.V. Sidorova, K.V. Safonov, European Journal of Contemporary Education, Contemporary didactics in higher education in Russia, 17, 357 (2016)

3. GOST R 53620-2009, Information and communication technologies in education. Electronic learning resource. General regulations, (2011).

4. P. Brusilovsky, Proceedings of the 4th Hellenic Conference on Information and Communication Technologies in Education, Adaptive educational hypermedia: from generation to generation, 19 (2004)

5. P. Brusilovsky, Kьnstliche Intelligenz, Adaptive and Intelligent Technologies for Webbased Education, 13, 19 (1999) 
6. Y.V. Vainshtein, R.V. Esin, G.M. Tsibul'skii, Informatics and Education, Adaptive model of developing individual educational trajectories for blended learning, 2, 83 (2017).

7. Y.V. Vainshtein, V.A. Shershneva, R.V. Esin, T.V. Zykova, Open Education Adaptation of mathematical educational content in e-learning resources, 21, 4 (2017).

8. P.P. D'iachuk, L.V. Shkerina, I.V. Shadrin, I.P. Peregudova, Bulletin of Krasnoyarsk State Pedagogical University named after V.P. Astafiev, Dynamic adaptive testing as a method of students' self-learning in the electronic problem environment of mathematical objects, 1, 48 (2018).

9. T.O. Kochetkova, O. A. Karnaukhova, Bulletin of Krasnoyarsk State Pedagogical University named after V. P. Astafiev, Adaptive educational strategy for web-based mathematics teaching, 2, 50 (2018).

10. V.A. Shershneva, Pedagogy, Development of mathematical competence for engineering students, 5, 62 (2014).

11. A.A. Kytmanov, M.V. Noskov, K.V. Safonov, M.V. Savelyeva, V.A. Shershneva, Mathematics Education Bulletin, Competency-based Learning in Higher Mathematics Education as a Cluster of Efficient Approaches, 30, 1113 (2016).

12. L.V. Shkerina, E.V. Senkina, G.S. Savolainen, Bulletin of Krasnoyarsk State Pedagogical University named after V. P. Astafiev, Interdisciplinary educational module as organizational and pedagogical condition of formation of research competences of future teacher of mathematics at university, 4, 76 (2013).

13. M. Lindner, Proceeding of the 13th International Conference of the Association for Learning Technology, Use these tools, your mind will follow. Learning in immersive micromedia and microknowledge environments, 41 (2006).

14. A. Schmidt, Proceedings of the 3rd International MicroLearning Conference, Microlearning and the Knowledge Maturing Process: Towards Conceptual Foundations for Work-Integrated Microlearning Support, 99 (2007).

15. I. Buchem, H. Hamelmann, eLearning Papers, Microlearning: A Strategy for Ongoing Professional Development, 21:7, 1 (2010).

16. S. Alsardary, P. Blumberg, Primus, Interactive, learner-centered methods of teaching mathematics, 19:4, 401 (2009).

17. M. Abdulwahed, B. Jaworski, A.R. Crawford, Nordic Studies in Mathematics Education, Innovative approaches to teaching mathematics in higher education: a review and critique, 17:2, 49 (2012).

18. L.V. Shkerina, P.P. Dyachuk, M.K. Gritskov, Bulletin of Krasnoyarsk State Pedagogical University named after V. P. Astafiev, Self-organisation of a student in the process of teaching to solve mathematical tasks in problem environment: synergetic approach, 2, 96 (2014)

19. G.A. Atanov, Educational Technology \& Society, The modeling of an educational subject domain or the subject model of a learner, 1, 111 (2001)

20. Y. Vainshtein, R. Esin, V. Shershneva, G. Tsibulsky, K. Safonov, SHS Web of Conferences, Adaptation algorithms of mathematical educational content in $e$ learning, 48 (2018).

21. V. Shershneva, Y. Vainshtein, T. Kochetkova, Program Systems: Theory and Applications, Adaptive system of web-based teaching, 39, 179 (2018) 